\title{
ESCREVER, HOJE - PALAVRA, IMAGEM E TECNO- LOGIAS DIGITAIS NA EDUCAÇÃO
}

José Teófilo de Carvalho

(CEFET-MG)

https://orcid.org/0000-0003-4201-6214

\begin{abstract}
RIBEIRO, Ana Elisa. Escrever, hoje - palavra, imagem e tecnologias digitais na educação. $1^{\text {a }}$ ed., São Paulo: Parábola Editorial, 2018, 128 p.
\end{abstract}

Escrever, hoje - palavra, imagem e tecnologias digitais na educação é o mais recente livro de Ana Elisa Ribeiro, lançado pela Parábola Editorial, em oito capítulos. O prefácio é de Carla Coscarelli e tem como subtítulo: escrita, leitura, poder e tecnologia.

O livro apresenta discussões, análises e questionamentos sobre o texto, nos aspectos relacionados às suas diversas manifestações, como a edição, a editoração, a leitura e a escrita nos ambientes, tanto impresso, como digital. O prefácio apresenta a autora como uma estudiosa do livro, do texto, da escrita e da leitura. Desse modo, a obra traduz seu pensamento e posicionamento de escritora, com vasta produção acadêmica e científica na última década. Somada à produção autoral, às orientações de pesquisas acadêmicas e práticas de sala de aula, o texto dá consistência a suas argumentações, no diálogo com autores consagrados da Linguística e dos Estudos de Linguagens. Desse olhar atento surgem novas teorias, novas hipóteses e questionamentos sobre a multimodalidade das linguagens na produção de textos, potencializadas ainda mais pelos recursos digitais que exigem também novos letramentos para recepção e compreensão do texto ampliado.

Discutidos como artefatos culturais, os textos envolvem, antes dos leitores, autores, editores, designers e demais profissionais da cadeia editorial, antes de se tornarem livros. Cada um desses profissionais faz escolhas, às vezes, conflitantes sobre temas, linguagens, formatos, recursos materiais e suportes para fazer um livro. 
O capítulo inicial, Cultura escrita, cultura impressa, cultura digital, traça um panorama sobre letramento digital e a cibercultura, em contraponto com a cultura impressa. Esta última, constituída há milênios, passou por vários materiais (argila, pedra, couro, tecidos, fibras vegetais e papel) e chega hoje à forma imaterial - bits. Em várias partes do mundo, estudiosos se dedicam ao estudo da cultura digital, desde a consolidação dos computadores e da internet. No Brasil, Pierre Lévy goza ainda de grande prestígio nas publicações sobre o hipertexto e cibercultura. A cibercultura para ele é um "conjunto de técnicas (materiais e intelectuais), de práticas, de atitudes, de modos de pensamento e de valores que se desenvolvem juntamente com o ciberespaço (rede)" (Lévy, 1999, p. 17). Não se entra na cultura digital só por adquirir um dispositivo, porém, o leitor do livro impresso não é passivo face à tensão gerada pela cultura digital. A transição do impresso ao digital se dá num continuum.

O capítulo "Nunca mais vejo um jornal do mesmo jeito" mostra a relação entre leitura, edição e letramento. A primeira oferece as informações sobre as práticas sociais e habilidades dos grupos de leitores e ainda sobre produtos editoriais consumidos. Desse modo, letramento e questões editoriais dialogam amplamente, uma vez que produtores se valem de informações dos leitores para produzir textos. As práticas de leitura e escrita, em nossa sociedade, tornaram-se mais exigentes e sofisticadas. Trouxeram assim novas demandas para leitores e produtores de texto. A conotação de letramento vai além da alfabetização, implica em práticas sociais, isto é, o agir na sociedade através da prática da leitura e da escrita. Essas questões estão ligadas ao que se lê, materiais consumidos, como são produzidos, publicados e oferecidos ao leitor. Tudo que lemos nos jornais, nos sites ou redes sociais, assistimos na TV e ouvimos no rádio passou por um processo de edição. Esse processo não é neutro, mas movido por escolhas e interesses; a mídia pode ampliar, reduzir ou até contradizer a informação recebida e transmitida.

A função da escola e da formação educacional, principalmente em Letras, consiste em estudar e investigar os processos de edição: 1) formar profissionais de edição, capazes de dar tratamento a textos originais, a fim de torná-los publicáveis; 2) formar leitores capazes de distinguir e analisar textos e produtos editoriais, de maneira menos ingênua e neutra. Mas, o caminho para isso, em larga escala, é tortuoso. Assim, em agências como a escola, as conexões entre letramento e o processo de edição são cada vez mais evidentes e necessárias, em um mundo de vozes diversas e 
concorrentes. Leitores analíticos e críticos favorecem muito a existência de um mundo mais horizontal e menos manipulado por poucos.

O capítulo Como centenas de "nativos digitais" lêem "ícones" retoma letramento, em Magda Soares (2004), quanto às "desagregações" ou estilhaçamento do conceito e seleciona dois letramentos para análise. No primeiro, o enfoque é no computador com as interfaces gráficas, os aplicativos e navegadores, permeados por ícones, o que exige um novo letramento - o digital. Facilitadas pelos recursos digitais, multiplicam-se a produção e circulação de imagens, exigindo também outro letramento - o visual. Esses letramentos separam a fronteira entre o analógico e o digital, entre "nativos" e "imigrantes" digitais, dicotomia polêmica, introduzida por Marc Prensky em 2001. Os primeiros já teriam os cérebros diferentes e seriam fisicamente adaptados a uma comunicação acelerada e multitarefa, moldados pela longa exposição à televisão e ao videogame, por terem nascidos após a popularização da informática. Os imigrantes se adaptaram a essa tecnologia, porém, a usam com "sotaque" e em desvantagem sobre os nativos (p. 44-45). A respeito dessa polarização, as pesquisas, dentro e fora do Brasil, identificam três grupos: no primeiro, os autores adotam essa dicotomia, sem criticá-la; no segundo grupo, os autores tecem uma crítica branda à teoria de Prensky, alertando para as questões culturais e generalizantes da proposta; um terceiro grupo tece críticas mais duras e mostra os "mitos" e "falatório" dos entusiastas desse tema.

Outro capítulo denomina-se Palavra \& criação, palavra \& ação, é fruto de observações e pesquisas recentes de mestrado na linha de pesquisa em edição, na Pós-graduação em Estudos de Linguagens numa instituição federal. Em comum, os temas discutem a relação entre a palavra e imagem, recorrendo, principalmente, à ideia de Kress (2003) sobre paisagem comunicacional, isto é, a prevalência da imagem no mundo contemporâneo. Para Kress, todo texto é sempre multimodal. Desse modo, os livros são muito mais do que apenas objetos em papel, de formato conhecido e identificado como tal; pode ser também uma tela de um computador, de um leitor de livros ou de um smartphone. Por isso, na relação palavra/imagem, deve-se estudar também o processo criativo e não apenas o produto final.

Consequentemente, todas as modalidades nas linguagens e todos os recursos tecnológicos são importantes e passíveis de serem selecionados e orquestrados, com finalidade educativa, mostra o capítulo Tecnologias na educação. As questões desafiadoras são as escolhas dos meios que fazem 
sentido usar, com determinada finalidade. Às vezes, é necessário ajustar a tecnologia aos propósitos para que a integração faça sentido e seja produtiva. Do quadro de giz à televisão ou rádio, usamos a palavra o tempo todo, porém, em certos textos, a integração entre linguagens e semioses se mostra mais adequada. Em estudos de novos letramentos e de multimodalidade, afirma Kress (2003, p.140): "A atual paisagem comunicacional pode ser caracterizada pela metáfora do dizer o mundo para o mostrar o mundo" (tradução e grifo da autora). Textos são mais do que palavras nessa paisagem comunicacional, contudo, o acesso às tecnologias digitais aumenta o "poder semiótico" de estudantes e professores.

Tecnologia e poder semiótico é outro capítulo sobre o papel da escola e trata do empoderamento dessa instituição, de forma especial, nas linguagens, ao atuar de forma responsável e pertinente, esforçando-se para não transmitir discursos deslumbrados e milagrosos sobre tecnologias. Num posicionamento crítico, o argumento é que não cabe mais discutir sobre se vamos usar recursos digitais na escola; a questão hoje é como e quais ferramentas ou linguagens empregar, para tais e quais objetivos e funções. Tudo passa primeiro pela escrita, por isso, ler e escrever são a base para pensarmos todas as formas de expressão de que dispomos hoje.

Este capítulo tem em Kress (2003) uma expressão que traduz bem o espírito desta obra: "comunicar é trabalhar para produzir sentido. Trabalhar é mudar as coisas. Essa é a razão pela qual gosto da metáfora 'paisagem comunicacional'. E deve ser também uma das razões que me fazem gostar dela" (p.82). Este conceito mostra o poder semiótico do texto e as possibilidades de boa redação, no vasto campo das linguagens, potencializados ainda mais pelas tecnologias digitais. "Escrever, hoje", subtítulo que dá nome ao livro, responde às perguntas feitas nos capítulos anteriores e mostra a escrita atual como a chance de manejar ferramentas para ampliar formas de expressão e de representação do texto. É o capítulo central do livro.

Outro capítulo, Tecnologia digital e ensino, aborda o problema do acesso ao conhecimento e da formação de leitores. Afastando-se de uma ideia redutora e desqualificadora da incapacidade do professor, as pesquisas sobre tecnologias digitais no ensino nas últimas duas décadas, no Brasil e no exterior, constatam a baixa adesão da escola aos recursos digitais. $\mathrm{O}$ texto não menciona políticas educacionais, porém, deixa transparecer que o uso intensivo de tecnologia digital na educação continua um tema atual, pertinente e relevante. Assim, o papel da escola consiste no empo- 
deramento do aluno ao se apropriar das diversas linguagens (literárias, visuais, digitais, midiáticas), de forma crítica. Esse poder oferece meios para que as pessoas leiam, leiam bem, reajam e produzam textos multimodais. Decorre daí o papel do professor que toma para si a tarefa de contar, mostrar, expor, propor, indicar, recomendar, avaliar, ler, cuidar e tantos outros verbos que se integram na palavra ensinar (p. 78, grifo da autora).

Mas, aprender não é tarefa só do estudante, continua; estende-se para fora da escola para professores, pais e dirigentes, já que os ambientes de letramentos vêm mais de fora do que de dentro da escola. Letramento, como prática social, inclui jovens e adultos, além de interação com linguagens, modalidades e semioses da paisagem comunicacional. As tecnologias digitais podem aumentar o poder semiótico da sociedade pelo uso de ferramentas que são disponibilizadas e que estendem o manejo das linguagens para além da escrita.

Por que, então, apesar das constatações anteriores e dos avanços dos últimos trinta anos, as tecnologias digitais não chegaram ao ensino, pelo menos, na velocidade desejada? Com base nas últimas pesquisas brasileiras, o capítulo sugere algumas ações para a tríade: tecnologia, ensino e aprendizagem. Na ação docente, o texto delineia seis elementos para se pensar e agir nas aulas, com cautela e de forma crítica: vontade de aprender, usar (recursos digitais), relacionar, experimentar, avaliar e gestão do tempo de trabalho. O professor saberá selecionar o que melhor lhe cabe, no momento; não se trata de receita pronta, algo definitivo.

Por fim, em Finalizar, por enquanto, apesar das condições materiais e da aridez da sala de aula, a autora nos instiga: “[...] o que move esta paisagem em direção à aprendizagem, de todos nós, é nossa curiosidade, nossa provocação mútua" (p.117). Na atuação profissional e pessoal, a escrita tem parecido merecer mais atenção, mais esforço, mais ação, pois, escrita é poder. Sem expressão, pode ser que uma massa de leitores se torne apenas uma massa que silencia suas boas ideias (p.118). Vivemos num mundo cercados de textos e nos comunicamos por meio deles. A teoria alimenta a prática e essa retroalimenta a teoria, em espiral, ampliando nossos recursos e competências para ler e escrever, incluídos professores, alunos, cidadãos... (p.119).

Pelo conteúdo, atualidade e provocações, o livro merece uma leitura atenta de professores, coordenadores e profissionais de ensino, preocupados com a questão de novos letramentos, hoje, no ambiente digital, sem perder de vista a tradição do impresso. Os meios digitais favorecem o em- 
prego de recursos multimodais na produção e na recepção dos textos, mas como se deve usá-los? O que faz sentido usar? O livro não esgota o tema, mas dá ainda boas dicas de reflexão e de leitura para novos pesquisadores e para projetos de pesquisa de novas semioses nas áreas de Linguística, de Estudos de Linguagens e de Educação.

\section{REFERÊNCIAS}

KRESS, Gunther. Literacy in the New Media. London/New York, Routledge, 2003.

LÉVY, Pierre. Cibercultura. Tradução de Carlos Irineu Costa. São Paulo: Editora 34, 1999.

PRENSKY, Marc. Digital natives, digital immigrants. On the Horizon. MCB University Press. v. 9, n. 5, out. 2001.

SOARES, Magda. Alfabetização letramento: caminho e descaminhos. Pátio Revista pedagógica, Artmed editora, 29 fev., 2004.

Recebido em: 22/11/2018

Aceito em: 19/06/2019 